ISSN 0258-7122

Bangladesh J. Agril. Res. 34(2) : 247-253, June 2009

\title{
CORRELATION AND PATH COEFFICIENT ANALYSIS IN FAT AND FATTY ACIDS OF RAPESEED AND MUSTARD
}

\begin{abstract}
M. S. ISLAM ${ }^{1}$, L. RAHMAN ${ }^{2}$ AND M. S. ALAM ${ }^{3}$
Abstract

Twenty-two genotypes of Brassica (B. rapa, B. juncea, and B. napus) were studied for correlation co-efficient between major fatty acids and path coefficient analysis to partition the cause and effect relationship into direct and indirect components. Correlation coefficient of major fatty acids revealed that significant and positive correlation was between palmitic and oleic acids, palmitic and linoleic acids, palmitic and cicosenoic acids, oleic and eicosenoic acids, linoleic and linolenic acids and eicosenoic and erucic acids, while significant and negative correlation was observed between palmitic and erucic acids, stearic and linolenic acids and oleic and erucic acids. Path coefficient revealed that direct effect of all fatty acids except palmitic acid on oil content was positive. Indirect effect of erucic acid through all other fatty acids except palmitic acid on oil content was negative, Indirect effect of palmitic acid via all other fatty acids except erucic acid was positive.
\end{abstract}

Key Words : Fat and fatty acids, Rapeseed and mustard.

\section{Introduction}

The genus Brassica belongs to the family Crucifereae. All the major Oleiferous species of this genus are grouped into two; rapeseed and mustard. Rapeseed mainly includes $B$. napus, $B$. rapa, and $B$. nappobrassica (Downy, 1965), while mustard encompasses the species like $B$. nigra, $B$. juncea, $B$. carinata, $B$. hirta and $B$. arvensis. These Brassica species are mainly grown for human and animal cosumption of fats and proteins. Brassica oil crops are the most important groups of species that supplies major edible oils in Bangladesh (BBS, 2002). Depending on their fatty acid composition, oils can be used as edible or as industrial one. Oils high in oleic and linoleic acids are valued for edible purposes, and those with proportionately higher quantity of linolenic, eicosenoic, and erucic acids are valued for industrial purposes. Erucic acid is believed to be responsible for health hazards of human being. Increasing seed yield and oil content and as well as improving oil quality are important factors for breeding of rapeseed and mustard.

Mean of individual fatty acid concentration among different species of the family Crucifereae are not similar because of the presence of different kinds of significant relationship among the individual fatty acids (Mandal et al., 2002). The relationship between various pairs of fatty acids has so far been established

\footnotetext{
${ }^{1}$ Scientific Officer, On-Farm Research Division, BARI, Sabujbag, Patuakhali-8600, ${ }^{2 \& 3}$ Professor, Department of Genetics and Plant Breeding, BAU, Mymensingh-2202, Bangladesh.
} 
by various workers (Genet et al., 2004; Sial et al., 2004; Patel et al., 2003; Chauhan et al., 2002; Rahman et al., 1999; Rudloff et al.., 1999). The decrease in erucic acid causes an increase in both oleic and linoleic acids and along with the decrease in erucic acid, eicosenoic acid decreases considerably (Rahman, 1976). Earlier emphasis was only given to indicate the relative importance of different component characters with respect to plant selection on the basis of their variabilities and interrelationship of quantitative characters among the genotypes. The direct and indirect associations among many characters become complex and important. In such circumstances, path coefficient analysis helps to find out the direct and indirect cause of association. Path coefficient analysis is a standardized partial regression coefficient analysis and as such measures the direct influence of one variable upon other and allows the partioning of correlation coefficient into direct and indirect effects of component characters. Path coefficient analysis has widely been used by the animal breeders to understand the cause and effect relationship of important characters. However, it has also been used in crop plant to analyze the real contribution of individual complex characters in yield. The term path coefficient was coined by Wright (1921) to denote the direct influence of variable (cause) upon another variable (effect) as measured by the standard deviation remaining in the effect after the influence of all other possible paths are estimated except that of cause. It was later elaborated by Niles (1923). Tukey (1954), Kempthrone (1957), and Li (1956) presented a detailed account of both basic and applied aspects of path analysis. The present study was, therefore, undertaken to find out the interrelationship between different fatty acids and the direct and indirect cause of association, which could help in quality breeding in rapeseed and mustard.

\section{Materials and Method}

The present study was carried out with twenty varieties of Brassica genus developed by different organizations of Bangladesh and two advanced lines. The genotypes were Daulat, Sonali (SS-75), Kallyania (TS-72), Rai-5, BARI Sarisa6. BARI Sarisa-7, BARI Sarisa-8, BARI Sarisa-9, BARI Sarisa-10, BARI SarisaI I, BARI Sarisa-12, and BARI Sarisa-13 developed by Bangladesh Agricultural Research Institute (BARI), Gazipur; Agrani, Safal, BINA Sarisa-3, BINA Sarisa4, BINA Sarisa-5, and BINA Sarisa-6 developed by Bangladesh Institute of Nuclear Agriculture (BINA), Mymensingh and Sampad and Sambal by Bangladesh Agricultural University (BAU), Mymensingh and two lines, viz., BJ536 and Nap-179 by BARI. The seeds were collected from the crops grown during Rabi season of 2004-05 from the respective organization. Quantification of fatty acids composition (\%) was performed with Gas Liquid Chromatography (GLC) method by Philips PU4500 Chromatograph in the Central Laboratory, BARI. Joydebpur, Gazipur. In the GLC column temperature was fixed at $185^{\circ} \mathrm{C}$, injector temperature was $220^{\circ} \mathrm{C}$ and the detector temperature was $240^{\circ} \mathrm{C}$. Fatty 
acid compositions (\%) were calculated from the chromatograph. Unit area for each peak of respective fatty acid was calculated against starting time by GLC. Fatty acid composition was calculated as follows

Factor $=\frac{100}{100 \text { - Unit area of solvent }}$

$\%$ fatty acid $=$ Unit area of respective fatty acid $\mathrm{x}$ Factor

Major fatty acids viz., palmitic, stearic, oleic, linoleic, linolenic, eicosenoic and erucic acids composition (\%) were subjected to correlation between them and the cause of association into direct and indirect components.

\section{Results and Discussion}

\section{Correlation between major fatty acids}

General correlations between major fatty acids are presented in Table 1 . Significant and positive correlation was observed between palmitic acid and oleic acid (0.577), palmitic acid and linoleic acid (0.562), palmitic acid and eiconesonic acid (0.554), oleic acid and eicosenoic acid (0.819), linoleic acid and linolenic acid (0.523) and eicosenoic acid and erucic acid (0.917), while significant and negative correlation was found between palmitic acid and erucic acid (-0.789), stearic acid and linolenic acid (-0.529), oleic acid and erucic acid (0.882 ) at p <0.01, considering all genotypes. Rahman et al. (1999); Patel et al. (2003); Sial et al. (2004); Genet et al. (2004) reported significant negative correlation between oleic acid and erucic acid. According to Loft and Appelqvist (1964) the relationship between $\mathrm{C}_{18}$ and $\mathrm{C}_{22}$ fatty acids in rapeseed (Summer and Winter) and white mustard were negative.

Considering only B. rapa, significant and positive correlation was observed between palmitic acid and linolenic acid (0.657), oleic acid and linoleic acid (0.804), oleic acid and linolenic acid (0.718), linoleic acid and linolenic acid (0.912), and eicosenoic acid and erucic acid (0.944), while significant and negative correlation as observed between palmitic acid and erucic acid (-0.680), stearic acid and linoleic acid (- 0.756), stearic acid and linolenic acid (-0.930), stearic acid and eicosenoic acid (-0.701), stearic acid and erucic acid (-0.751), linoleic acid and erucic acid (-0.713), linoleic acid and eicosenoic acid (-0.711) and linolenic acid and erucic acid (-0.818).

Similarly correlation between major fatty acids of $B$. juncea seed oil was determined. Significant and positive correlation was observed between palmitic acid and oleic acid (0.888), stearic acid and oleic acid (0.783), oleic acid and linolenic acid (0.778) and between ecosenoic acid and erucic acid (0.855), while significant and negative correlation was observed between stearic acid and 
linolenic acid (-0.898), linolenic acid and erucic acid (-0.729), linolenic and eicosenoic acid (-0.763).

Table 1. Relatinship between various pairs of fatty acids in Brassica seed oils.

\begin{tabular}{|c|c|c|c|c|}
\hline \multirow[t]{2}{*}{ Pairs of fatty acids } & \multicolumn{4}{|c|}{ Values of "r" with significant level } \\
\hline & Brassica spp. & B. rapa & B. juncea & B. napus \\
\hline \multicolumn{5}{|l|}{ Palmitic - } \\
\hline - Stearic & +0.323 & -0.298 & +0.579 & $10933 * *$ \\
\hline - Oleic & $+0.577 * *$ & +0.308 & $0.888 * *$ & +0.623 \\
\hline - Linoleic & $+0.562 * *$ & +0.113 & +0.205 & +0.428 \\
\hline - Linolenic & +0.264 & +0.284 & -0.521 & +0.268 \\
\hline - Eicosenoic & $+0.554 * *$ & $+0.657^{*}$ & +0.416 & +0.589 \\
\hline -Erucic & $0.789 * *$ & $0.680^{*}$ & -0.110 & $0.882 * *$ \\
\hline \multicolumn{5}{|l|}{ Stearic - } \\
\hline - Oleic & +0.277 & +0.633 & $+0.783^{*}$ & $+0.738 *$ \\
\hline - Linoleic & -0.146 & $0.756^{*}$ & -0.155 & +0.341 \\
\hline - Linolenic & $0.529 * *$ & $0.930 * *$ & $0.898 *$ & -0.069 \\
\hline - Eicosenoic & -0.091 & $0.701^{*}$ & -0.532 & -0.320 \\
\hline - Erucic & -0.105 & $0.751 *$ & -0.531 & $0.785^{*}$ \\
\hline \multicolumn{5}{|l|}{ Oleic - } \\
\hline - Linoleic & +0.142 & $+0.804^{* *}$ & +0.004 & +0.283 \\
\hline - Linolenic & -0.396 & $+0.718^{*}$ & $+0.778^{*}$ & +0.283 \\
\hline - Eicosenoic & $+0.819 * *$ & -0.365 & -0.535 & +0.091 \\
\hline - Erucic & $0.882 * *$ & -0.406 & -0.424 & -0.668 \\
\hline \multicolumn{5}{|l|}{ Linoleic - } \\
\hline -Linolenic & $+0.523 * *$ & $+0.912 * *$ & -0.087 & +0.395 \\
\hline - Eicosenoic & +0.155 & +0.552 & -0.671 & +0.594 \\
\hline - Erucic & -0.339 & $0.713^{*}$ & -0.328 & $0.733 *$ \\
\hline \multicolumn{5}{|l|}{ Linolenic - } \\
\hline - Eicosenoic & -0.006 & $-0.711 *$ & $0.763^{*}$ & $0.743^{*}$ \\
\hline -Erucic & -0.045 & $0.818^{* *}$ & $0.729 *$ & -0.328 \\
\hline \multicolumn{5}{|l|}{ Eicosenoic - } \\
\hline - Erucic & $+0.917 * *$ & $+0.944 * *$ & $+0.855^{*}$ & $+0.742 *$ \\
\hline
\end{tabular}

${ }^{* *} \mathrm{p}<0.01,{ }^{*} \mathrm{p}<0.05$

In the same way, correlation between major fatty acids of $B$. napus seed oil was determined. Significant and positive correlation was observed between 
palmitic acid and stearic acid (0.933), stearic acid and oleic acid (0.738) and between ecosenoic acid and erucic acid was (0.742), while significant and negative correlation was between palmitic acid and erucic acid (-0.882), stearic acid and erucic acid (-0.785), linoleic acid and erucic acid (-0.733) between linolenic acid and ecosenoic acid (-0.743).

Basudev Singh et al. (2001) reported significant and positive correlation between Palmitic acid and oleic, linoleic, linolenic and eicosenoic acids; between stearic acid and oleic acid; between oleic acid and linoleic acid; between linoleic acid and linolenic acid and significant and negative correlation was between stearic acid and eiconesic and erucic acids; between oleic acid and eicosenoic and erucic acids and between erucic acid and all other fatty acids except eicosenoic acid. Rahman et al. (1999) observed positive and significant correlation between palmitic acid and oleic and linoleic acids; between oleic acid and linolenic acid; between linoleic acid and linolenic acid and between eicosenoic acid and erucic acid.

\section{Path analysis}

In order to find out a clear picture of the interrelationship between oil content and major fatty acids, direct and indirect effects were worked out using path analysis. Oil content was considered as a dependent variable and palmitic acid, stearic acid, oleic acid, linoleic acid, linolenic acid, eicosenoic acid and erucic acid were independent variables. The estimates of direct and indirect effects estimated from general correlation have been presented in Table 2.

Table 2. Path coefficient showing direct (bold) and indirect effects of major fatty acids on oil content in twenty two Brassica genotypes of Bangladesh.

\begin{tabular}{c|c|c|c|c|c|c|c|c}
\hline $\begin{array}{c}\text { Fatty } \\
\text { acids }\end{array}$ & $\begin{array}{c}\text { Palmitic } \\
\text { acid } \\
\text { (C16:0) }\end{array}$ & $\begin{array}{c}\text { Stearic } \\
\text { acid } \\
\text { (C18:0) }\end{array}$ & $\begin{array}{c}\text { Oleic } \\
\text { acid } \\
\text { (C18:1) }\end{array}$ & $\begin{array}{c}\text { Linoleic } \\
\text { acid } \\
\text { (C18:2) }\end{array}$ & $\begin{array}{c}\text { Linolenic } \\
\text { acid } \\
\text { (C18:3) }\end{array}$ & $\begin{array}{c}\text { Eicosenoic } \\
\text { acid } \\
\text { (C20:1) }\end{array}$ & $\begin{array}{c}\text { Erucic } \\
\text { acid } \\
\text { (C22:1) }\end{array}$ & $\begin{array}{c}\text { Oil } \\
\text { content }\end{array}$ \\
\hline C16:0 & $\mathbf{- 0 . 6 1 6}$ & 0.067 & 0.505 & 0.043 & 0.181 & 0.456 & -0.428 & -0.208 \\
C18:0 & -0.188 & $\mathbf{0 . 3 0 6}$ & 0.528 & -0.011 & -0.263 & -0.075 & -0.190 & -0.107 \\
C18:1 & -0.335 & 0.057 & $\mathbf{0 . 9 7 0}$ & 0.011 & -0.472 & 0.072 & -0.843 & $0.413^{*}$ \\
C18:2 & -0.146 & -0.030 & 0.269 & $\mathbf{0 . 0 7 7}$ & 0.359 & 0.242 & -0.614 & -0.157 \\
C18:3 & -0.163 & -0.109 & -0.287 & 0.340 & $\mathbf{0 . 6 8 7}$ & -0.005 & -0.081 & -0.382 \\
C20:1 & -0.341 & -0.029 & 0.155 & 0.012 & -0.304 & $\mathbf{0 . 8 2 0}$ & -0.675 & 0.362 \\
C22:1 & 0.486 & -0.122 & -0.673 & -0.226 & -0.031 & -0.752 & $\mathbf{0 . 5 2 6}$ & -0.208 \\
\hline
\end{tabular}

${ }^{*} \mathrm{p}<0.05$ 
Palmitic acid : The direct effect of palmitic acid on oil content was negative (0.616). Palmitic acid contributed indirectly through oleic acid (0.505) and eicosenoic acid (0.456). Palmitic acid contributed indirectly through all other fatty acids positively except erucic acid (-0.428).

Stearic acid : The direct effect of stearic acid on oil content was positive (0.306) but less. Stearic acid contributed indirectly through all other fatty acids negatively except oleic acid (0.528).

Oleic acid : The direct effect of oleic acid on oil content was highly positive (0.970). Oleic acid contributed indirectly through erucic acid (-0.843) highly and negatively followed by linolenic acid $(-0.472)$. The indirect effect of oleic acid through palmitic acid, linolenic acid and erucic acid was negative, while through stearic acid, linoleic acid and eicosenoic acid was positive.

Linoleic acid: The direct effect of linoleic acid on oil content was positive (0.077) hut low. Highly negative indirect effect of linoleic acid through erucic acid (-0.6 14) was observed. The indirect effect of linoleic acid through palmitic acid, stearic acid, and erucic acid was negative, while oleic acid, linolenic acid and eicosenoic acid was positive.

Linolenic acid: The direct effect of linolenic acid on oil content was positive (0.687). Linolenic acid contributed indirectly through oleic acid (-0.751) negatively. Linolenic acid contributed indirectly through all other fatty acids negatively except linoleic acid.

Eicosenoic acid : The direct effect of eicosenoic acid on oil content was moderately positive (0.820). Highly indirect effect of eicosenoic acid through erucic acid (0.675) was observed. Eicosenoic acid contributed indirectly through all other fatty acids negatively except oleic acid and linoleic acid.

Erucic acid : The direct effect of erucic acid on oil content was positive (0.526). Highly negative indirect effect of erucic acid through oleic acid (0.673) was observed. Erucic acid contributed indirectly through all other fatty acids negatively except palmitic acid.

\section{References}

Basudev Singh, J. N. Sachan, S. P. Singh, D. P. Pant, R. A. Khan, Rakesh Kumar, B. Singh and R. Kumar. 2001. Correlation among fatty acids of Brassica and related species. Crucifereae Newsletter. 23: 9-10.

BBS (Bangladesh Bureau of Statistics). 2002. Planning Divn., Ministry of Planning, Govt. of the People's Republic of Bangladesh. p : 130.

Chauhan, J. S., Poonam Tyagi, M. K. Tyagi and P. Tyagi. 2002. Inheritance of erucic acid content in two crosses of Indian mustard (Brassica juncea L.). SABRAO J. of Breeding and Genetics. 34(1): 19-26. 
Downey, R. K. 1965. Breeding for fatty acid composition in oils of Brassica napus L. and B. campestris L. EUCARPIACIQ Congress, $14^{\text {th }}-17^{\text {th }}$ July, 1965. p: $171-130$.

Genet, T.. M. T. Labuschagne and A. Hugo. 2004. Capillary gas chromatography analysis of Ethiopian mustard to determine variability of fatty acid composition. J. Sci. of Food and Agric. 84(13): 1663-1670.

Kempthrone, 0. 1957. An introduction to genetical statistics. John Wiley and Sons, Inc. New York. p : 545.

Li, C. C. 1956. The concept of path coefficient and its impact on population genetics. Biometrics 12: 190-2 10.

Loft, B. and L. A. Appelqvist. 1964. Breeding work in rape, turnip rape and white mustard in connection with research on the composition of fatty acids. Zeitschrift fur pffanzen Zuchtung 52(2): 118-126

Mandal, S., Sangita Yadav, Ranabir Singh, Gulnaz Begum, Poonam Suneja, M. Singh, S. Yadav, R. Singh, G. Begum and P. Suneja. 2002. Genetic Resources and Crop Evolution 49(6): 551-556.

Niles, N. E. 1923. The method of path coefficient as an answer to Wright. Genetics 8: 256-260.

Patel, K. M.. K.P. Prajapati, C. J. Pate! and N. P. Patel. 2003. Variability and correlation studies for fatty acids in Indian mustard. Brassica 5(3-4): 72-74.

Rahman, M. H., 0. Stolen, L. Rahman and M. M. Rahman. 1999. Composition and correlation studies of fatty acids in seed oi! of yellow sarson (Brassiea campestris L.) cuitivars and backcrosses derived zero erucic acid yellow sarson populations. $J$. National Sci. Foundation of Sri Lanka 27(2): 99-106.

Rahman, L. 1976. Breeding for oil content and composition in Oleiferous Brassica. Genetics and Plant Breeding Department Research Bulletin. No. 1, 1976. p : 16-1 8

Rudloff E., H. U. Jurgens, B. Ruge and P. Wehling.1999. Selection in transgenic lines of oilseed rape (Brassica rape L.) with modified seed oil composition. Proc. of the Int. Rapeseed Congress, Canbera, Australia, 1999. p : 132-136.

Sial, P., B. Singh, J. N. Sachan, and R. K. Pattnaik. 2004. Correlation among quality traits in toria (Brassica rapa L. sp. toria). Env. and Ecology 22(2) : 3 16-318.

Tukey, J. W. 1954. Causation, segregation and path analysis of causal path. Biometrics. 15: $236-258$.

Wright, S. 1921. Correlation and causation. J. Agric. Res. 20: 557-587. 